\title{
Tearful relations: oxidative stress, inflammation and eye diseases
}

\author{
Relações lacrimejantes: estresse oxidativo, inflamação e doenças oculares
}

\author{
Tais Hitomi Wakamatsu ${ }^{1}$ \\ Murat Dogru² \\ Kazuo Tsubota ${ }^{3}$
}

\footnotetext{
${ }^{1} \mathrm{PhD}$. candidate, Keio University School of Medicine, Department of Ophthalmology and Johnson and Johnson Ocular Surface Visual Optics Department. Tokyo - Japan.

${ }^{2}$ Associate Professor, Keio University School of Medicine, Johnson and Johnson Ocular Surface Visual Optics Department. Tokyo - Japan

${ }^{3}$ Professor and Chairperson, Keio University School of Medicine, Department of Ophthalmology. Tokyo Japan.

Corresponding author: Dr. Murat Dogru, Johnson\&Johnson. Department of Ocular Surface and Visual Optics, Keio University Schoool of Medicine. Tokyo - Japan.

Shinanomachi 35, Shinjuku-ku. Tokyo 160-8582, Japan E-mail: muratodooru@yahoo.com
}

\section{ABSTRACT}

Oxidative stress is caused by an imbalance between the production of reactive oxygen species and ability the biological systems' defense mechanisms necessary to eliminate the stress. It has been accepted that oxidative stress is involved in many acute and chronic diseases and even in normal aging. Recently, increased awareness of oxidative stress damage and its relation with ocular surface diseases incite researchers to discover possible mechanisms in the development of dry eye disease. This review focuses on the evaluation of the influence of oxidative stress on eye diseases emphasizing its relation with the pathogenesis of dry eye disease.

Keywords: Oxidative stress; Tears/enzymology; Eye diseases; Dry eye syndromes

\section{INTRODUCTION}

Cells generate energy by reducing molecular oxygen to water. During this process, small amounts of partially reduced reactive oxygen forms are produced as an unavoidable by-product of mitochondrial respiration. Some of these forms are free radicals that can cause cell injury. They are referred to as reactive oxygen species (ROS). Cells have defense systems to prevent injury caused by these products. An imbalance between free radical-generating and radicalscavenging systems results in oxidative stress, a condition that has been associated with the cell injury seen in many pathologic conditions. The effects of these reactive species are wide-ranging, but three reactions are particularly relevant to cell injury: lipid peroxidation of membranes, oxidative modification of proteins, oxidative damage to DNA.

In humans, oxidative stress is involved in many diseases, such as neurodegenerative disorders, including Parkinson's disease, Alzheimer's disease and amyotrophic lateral sclerosis, cardiovascular diseases, cancer and ischemic cascade due to oxygen reperfusion injury followed by hypoxia. Oxidative stress has become increasingly accepted as playing a role in the aging process. Oxidative damage has also been reported to play a role in several ocular diseases including age-related macular degeneration ${ }^{(1)}$, cata$\operatorname{ract}^{(2)}$, uveitis ${ }^{(3)}$, retinopathy of prematurity ${ }^{(4)}$, corneal inflammation ${ }^{(5)}$ and keratitis $^{(6)}$.

The toxic effect of these reactive oxygen species and free radicals can be eliminated by enzymes such as superoxide dismutase (SOD) which eliminates $\mathrm{O}_{2}$ - to produce $\mathrm{H}_{2} \mathrm{O}_{2}{ }^{(7)}$. This is eliminated by glutathione peroxidase or by catalase (Figure 1).

The effects of oxidative stress depend upon the size of the damage. A cell is able to overcome small perturbations and regain its original state; 


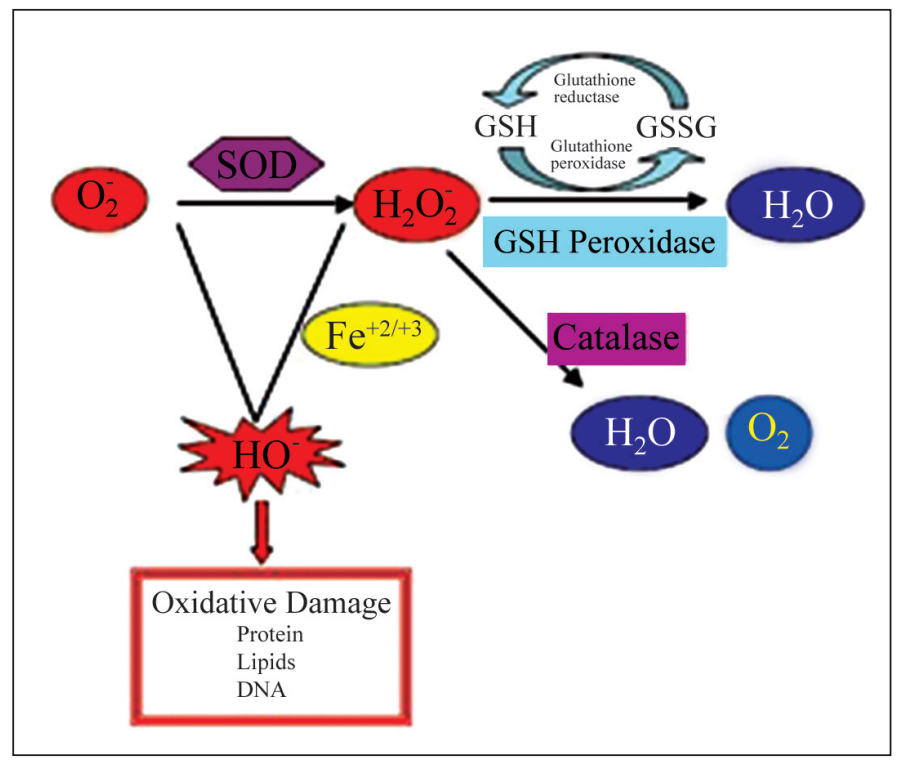

Figure 1 - An unbalance between the production of prooxidants and antioxidants in cells might lead to a strengthened production of free radicals like activated oxygen $\left(\mathrm{O}_{2}\right)$ and reactive oxygen species which could lead to serious celular damage

however, more severe oxidative stress can cause cell death, and even moderate oxidation can trigger apoptosis, while more intense stresses may causes necrosis ${ }^{(8)}$. SOD is one of the main antioxidant systems and is made up of three components: $\mathrm{Cu}$ $\mathrm{Zn-SOD}$ (SOD1) exists in the cytosol, Mn-SOD (SOD2) in the mitochondrial matrix, and extracellular SOD (SOD3) in the tissue as the secretory form ${ }^{(9)}$.

Because the superoxide anion radical substrate poorly penetrates membranes, the SOD isoenzymes primarily exert their protective functions in their respective compartments. Specific analysis of all three isoenzymes is therefore necessary to understand the protection of tissues against the superoxide radical.

Behndig et al. reported the activities of SOD isoenzymes in tears, cornea, sclera, aqueous humor, lens, vitreous body, and retina of the human eye. According to this study, the highest activity was found in the retina. The sclera and cornea had less SOD activity than the retina and the tears contain little SOD activity ${ }^{(10)}$. The inflammatory reaction is an important source of oxygen-free radicals. Large amounts of superoxide radicals are secreted by activated phagocytic leukocytes ${ }^{(11)}$, and the radical is also formed as a by-product during prostaglandin and leukotriene biosynthesis ${ }^{(12)}$. Ocular tissue and fluids, except the retina, possess little protection against superoxide radicals that would be formed during an inflammatory reaction.

These findings probably have been receiving attention of researchers to investigate the influence of oxidative stress in ocular diseases. Recently, the increased awareness of oxidative stress damage and its relation with ocular surface diseases incite researchers to discover possible mechanisms in the development of dry eye disease.

\section{Pathogenesis of dry eye}

\section{Oxidative stress and inflammation}

Dry eye was is described in the 2007 World Dry Eye Workshop Report as a multifactorial disease of the tears and ocular surface that results in symptoms of discomfort, visual disturbance, and tear film instability with potential damage to the ocular surface.

Whatever the initial cause of dry eye disease, chronic dryness of the ocular surface results in excessive nervous stimulation aimed at triggering the mechanisms of regulation and repair. It has been hypothesized that these nervous stimuli lead to neurogenic inflammation, activation of T-cells, and the subsequent release of inflammatory cytokines into the lacrimal glands, tear fluid, and conjunctiva ${ }^{(12)}$. When expressing human leukocyte antigen (HLA) DR class II antigens ${ }^{(13)}$, epithelial cells of the ocular surface and the lacrimal glands may acquire antigen-presenting capability, as demonstrated in corneal epithelial cells $^{(14)}$ and lacrimal acinar cells ${ }^{(15)}$. It may, thus, be hypothesized that immunologically activated epithelial cells can be targeted by lymphocytes in cytotoxic reactions ${ }^{(13)}$, and/or that they participate in the recruitment of inflammatory cells. These inflammatory reactions of the ocular surface result in gradual dysfunction and destruction of the lacrimal glands and impairment of the conjunctival epithelium. In addition, inflammatory mediators may inhibit neural signals to the lacrimal gland ${ }^{(16)}$, thus depriving the gland of the trophic stimulation needed for its maintenance and resulting in its progressive destruction. In addition, inflammation may finally influence tear film components other than those depending on the lacrimal gland, as interferon gamma, a major cytokine known to induce both HLA DR expression and apoptosis in conjunctival cells ${ }^{(13)}$, which has been shown to inhibit mucus production in the airways. Studies using immunological techniques have indeed shown the presence of conjunctival inflammation in more than $80 \%$ of patients with keratoconjunctivitis sicca $(\mathrm{KCS})^{(17-18)}$. The presence of inflammatory cell infiltrates in the lacrimal glands and the conjunctiva, the upregulation of immune-related antigens and inflammatory cytokines at the level of the conjunctival epithelium, impaired apoptotic regulation of lacrimal glands, and possible alterations in membrane trafficking of acinar cells, in association with squamous metaplasia and loss of globet cells, are common features of $\operatorname{KCS}^{(13,15,18)}$.

Whatever the initial mechanism, dry eye results in epithelial lesions that, beyond a certain level of cellular degeneration, result in local inflammatory reactions. It is hypothesized that subclinical hormonal or autoimmune factors aggravated by exogenous factors such as pollution, local infection, or allergic or iatrogenic phenomena result in a cascade of cellular reactions, in which apoptosis may be closely linked. Once dry eye disease has developed, inflammation becomes the key mechanism of ocular surface injury, as both the cause and consequence of cell damage. Patients with severe dry eye disease thus find themselves trapped in a vicious cycle of inflammation and ocular surface injury. 
Oxidative stress has recently been linked to the corneal, conjunctival and lacrimal gland injury that is associated with certain ocular surface conditions. Whether it is a primary cause or merely a downstream consequence of the inflammatory process is still an open question, however. The advent of a growing number of in vivo and in vitro models that emulate human disease pathology is aiding scientists in deciphering just where oxidative stress intersects with the cellular events in the emerging study of this relation.

Nakamura et al. demonstrated that superficial punctate keratopathy (SPK) was accompanied by an increase of oxidative stress markers, the expression in antioxidant-related gene, and ROS production in corneal epithelia. These results suggest a strong relationship between the accumulation of oxidative stress and the etiology of corneal epithelial alterations in blink-suppressed dry eye ${ }^{(19)}$ (Figure 2).

The biochemical study by Augustin et al. ${ }^{(20)}$ on the oxidative reactions in tears of patients with dry eye confirmed a marked increase of inflammatory activity in the tear film of patients suffering from dry eye. Lipid peroxide levels, as measured by the thiobarbituric acid method and myeloperoxidase activity, as parameters for oxidative tissue damage and inflammatory activity were determined. The authors concluded that both oxidative tissue damage and polymorphonuclear leukocytes indicating an oxidative potential occur in the tear film of patients with dry eyes. These reactions lead to severe damage of the involved tissue. Free radicals and inflammation may be involved in the pathogenesis or in the self-propagation of the disease. Their results did not distinguish satisfactorily between cause and effect of oxidative damage and the inflammatory activity of the eye surface, nor could they clarify whether oxidative damage was related directly to the pathogenesis of dry eye. However, what is known about oxidative reactions and changes due to dry eye syndrome can be used as a basis for various hypotheses that may explain their findings.

ROS not only has harmful functions as a by-product of cellular metabolism but also has an important role in cell signaling and regulation, and the balance between the formation and detoxification of ROS is tightly controlled by a homeostatic mechanism ${ }^{(21)}$. To measure the delicate balance that exists between ROS and the system in place to regulate them has given rise to several tools for the adequate detection and quantification of their influence. Emphasis is now being placed on biomarkers of oxidative stress, which are objectively measured and evaluated as indicators of normal biological processes, pathologic processes, or pharmacologic responses to therapeutic intervention. To be a predictor of disease, a biomarker must be validated. Validation criteria include intrinsic qualities such as specificity, sensitivity, degree of inter- and intraindividual variability, and knowledge of the confounding and modifying factors. In addition, characteristics of sampling and analytical procedures are of relevance, including constraints and noninvasiveness of sampling, stability of potential biomarkers, and the simplicity, sensitivity, specificity, and speed of the analytical method.
The localization and effects of oxidative stress, as well as information regarding the nature of the OS, may be gleaned from the analysis of discrete biomarkers of oxidative stress damage isolated from tissues and biological fluids. Because molecular products formed from the reaction of ROS with biomolecules are generally considered more stable than ROS themselves, most commonly ROS have been tracked by measuring stable metabolites and/or concentrations of their oxidation target products and oxidized proteins.

To function as suitable biomarkers of oxidative modifications in relation to disease, it is critical that such oxidation products are (a) a stable product, not susceptible to artifactual induction, oxidation, or loss during sample handling, processing, analysis, and storage; (b) a major product of oxidative damage that may be implicated directly in the onset and/or progression of disease; (c) accessible in a target tissue or valid surrogate that quantitatively reflects the oxidative modification of the target tissue; (d) present at concentrations high enough for the biomarker to be a significant product; (e) specific for the reactive species in question and free of confounding factors of dietary intake; (f) noninvasive; (g) measurable by assay that is specific, sensitive, and reproducible; (h) easy to detect and measurable across populations; (i) present in concentrations that not vary widely in the same persons under the same conditions at different times; (j) measurable with relatively small within-assay intrasample variation compared with between-person variations, so that they can be used as diagnostic tools ${ }^{(22)}$.

Useful tools to assay the presence and quantification of some oxidative biomarkers can be summarized as:

- Lipids; malondialdehyde (MDA), 4-hydroxy-2-nonenal (HNE), 2-propenal (acrolein), hexanoyl-lysine adduct (HEL), and isoprostanes.

- Proteins: dibromo-tyrosine (DiBrY), dityrosine (DT), aconitase, a1-antiproteinase, nitrotyrosine, and carbonylated proteins.

- DNA: 8-hydroxy-20-deoxyguanosine (8OHdG), and thymidine glycol (TG).

\section{Oxidative stress and the impact of adverse environmental conditions on the ocular surface}

The ocular surface is the most environmentally exposed mucosal surface of the body, encountering challenges such as wind, temperature extremes, ultraviolet irradiation, irritants, pollutants and tabacco smoke. Such factors, somehow, can influence the severity of ROS potential damage. As we previously described, the blink-suppressed dry eye model rat was obtained exposing the rats to continuous low-humidity airflow. This dry environment, as an adverse condition, suggests a strong relationship between accumulation of oxidative stress and the etiology of corneal surface disorder ${ }^{(19)}$.

Acute exposure to UV-B causes cell shedding of the corneal epithelium, and is often observed clinically in patients exposed to excessive solar radiation or welding arcs. Damaged epithelial cells have been demonstrated histogically on the 
A

Non-treatment

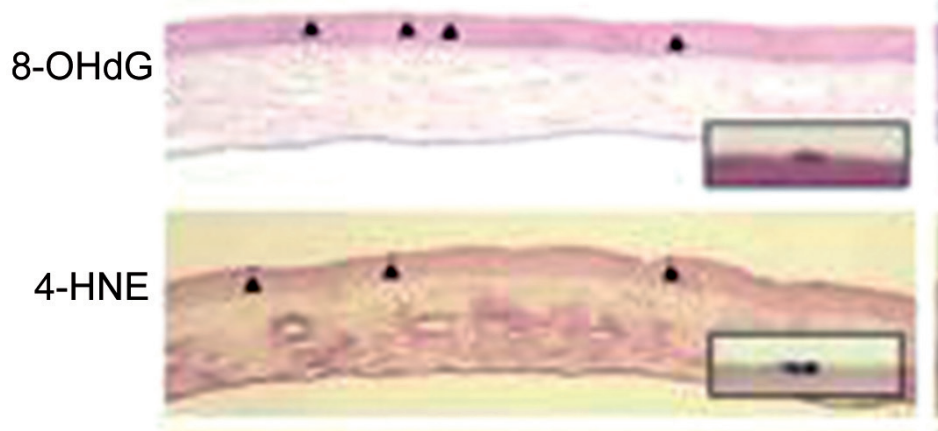

MDA

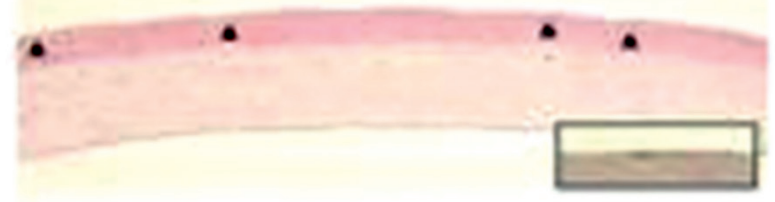

1st Ab

(*)

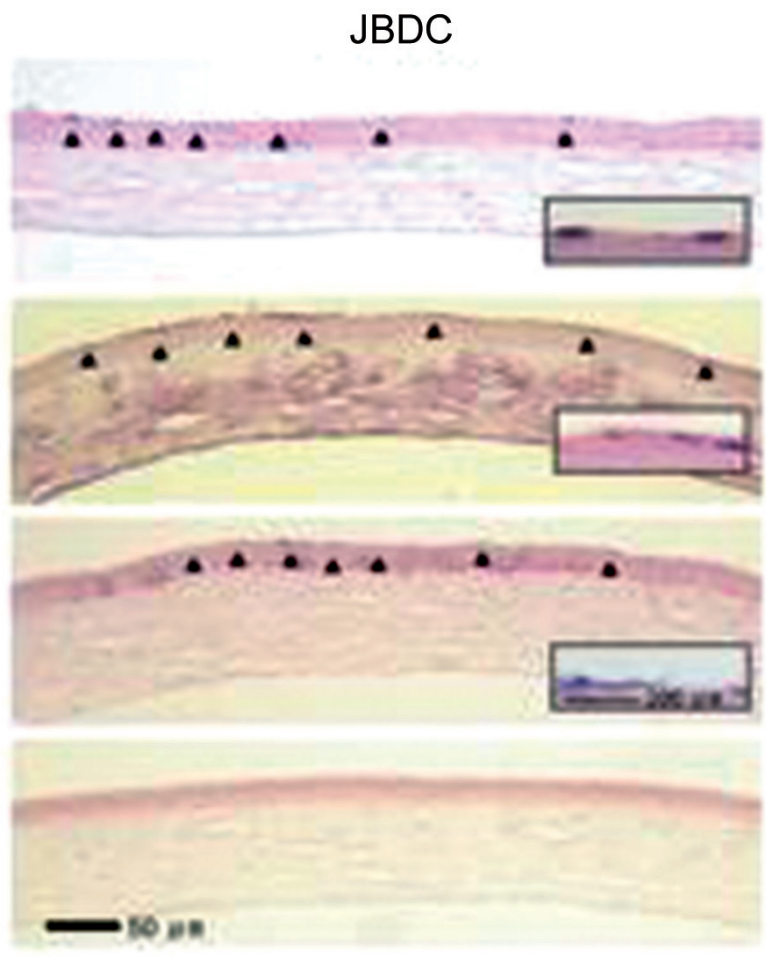

- Non-treatment

JBDC

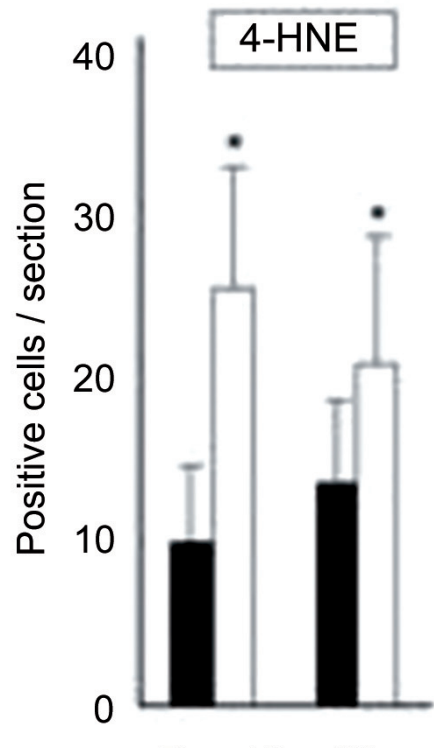

Day $10 \quad 30$

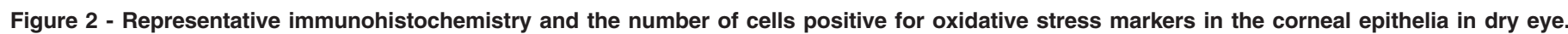

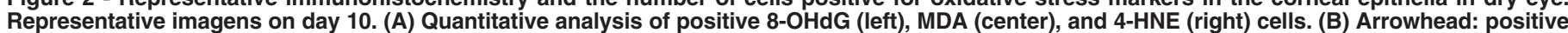

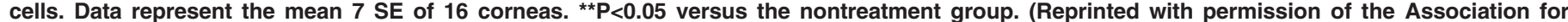

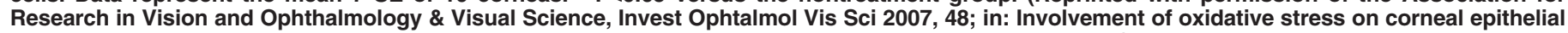
alterations in a blink-suppressed dry eye. Page 1555, Figure 3). 
surface of the cornea following UV irradiation ${ }^{(23)}$, and observation of desquamated cells by acridine orange have revealed epithelial cells with loss of polygonal shape and nuclear fragmentation ${ }^{(24)}$. Shimmura et al. demonstrated experimentally that subthreshold UV-B causes significant intracellular peroxide formation in corneal epithelial cells, and that lactoferrin in tears may play a physiological role in protecting the corneal epithelium from the solar UV irradiation. Corneal endothelial cells also seem to be affected by UV-B exposure presenting apoptosis that appears to result from a prooxidant/ antioxidant imbalance due to inactivation of antioxidant enzymes, mainly catalase, glutathione peroxidase and lactate dehydrogenase ${ }^{(25)}$.

Increased air pollution over the course of the past 20 years, coinciding with increased incidence of dry eye may support the contention that oxidative reactions are directly related to the pathogenesis of dry eyes. Ozone is known to permanently damage and inhibit the activity of enzyme groups such as lysozymes $^{(26)}$.

The increased occurrence of eye surface infections and the uncontrolled development of inflammations typical of dry eye have been reported to be a result of the reduced amount of lactoferrin in the tear film. Lactoferrin has an antioxidant effect in that it binds free iron, thus preventing the production of hydroxyl radicals. An adequate supply of lactoferrin is required to ensure functioning intracellular germ control ${ }^{(26-27)}$. Lactoferrin has been reported to be decreased in dry eye. A recent report showed improvement of tear stability and ocular surface damage by oral lactoferrin supplementation in patients with Sjögren's syndrome, suggesting that reduced lactoferrin activity observed in dry eyes may likely be the direct result of reduced enzyme production in the previously damaged lacrimal glands ${ }^{(28)}$.

Cigarette smoking has been reported to be one of the factors in the array of clinical conditions, resulting in a dysfunctional tear film ${ }^{(29-30)}$. It is well known that tears and gas phases of tobacco contain many oxidizing substances exposing inhalers to an enormous free radical load ${ }^{(31)}$. Matsumoto et al., confirmed the deleterious effect of chronic cumulative tabacco smoke exposure on the tear film and the increase in tear HEL (hexanoyl-lysine) levels, an oxidative stress marker for lipid peroxidation (Figure 3$)^{(32)}$. Same findings were observed by Rummenie et al., following passive cigarette smoke exposure ${ }^{(33)}$. Deleterious effect of even brief passive tobacco smoke on the tear film and ocular surface health status is evidenced by an increase of tear inflammatory cytokines, lipid peroxidation products and decrease of mucosal defense resulting in tear instability and damage to the ocular surface epithelia (Figure 4).

\section{Oxidative stress and aging eyes}

The prevalence of aqueous deficient type of dry eye is known to be high among the elderly ${ }^{(34)}$. As reported previously, the quality and quantity of tear fluid change during aging. These physiological changes that may predispose to dry eye, include decreased tear volume and flow, increased osmolarity, decreased tear film stability, and alterations in the com-

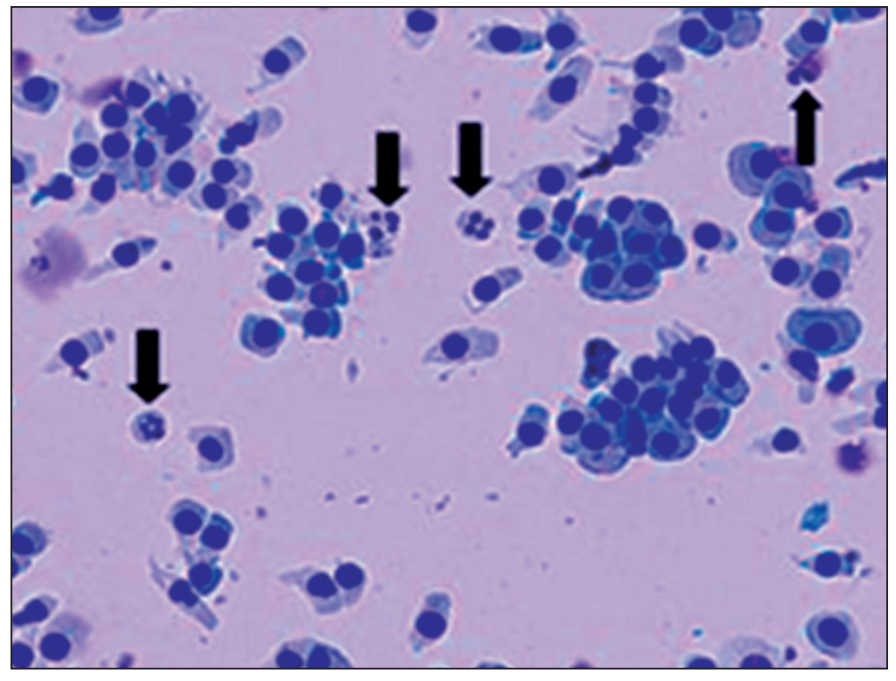

Figure 3 - Representative conjunctival brush cytology specimen from a chronic heavy smoker subject. Note the presence of numerous neutrophils (blue arrows), which was a consistent finding in specimens from smoker subjects. (Reprinted with permission from Nature Publishing Group, Eye, 2008 Jul;22(7); in: Alterations of the tear film and ocular surface health in chronic smokers. Page 966, Figure 4.)

position of the meibomian lipids. With increasing age in the normal human population, there is an increase in ductal pathology that could promote lacrimal gland dysfunction by its obstructive effect ${ }^{(35-36)}$. Damato et al. found lymphocytic glandular infiltrates in $70 \%$ of studied lacrimal glands and considered this to be the basis of fibrosis ${ }^{(35)}$. They postulated a sequence of periductal fibrosis, interacinar fibrosis and, finally, acinar atrophy. One of the most prominent changes that occurred in the mouse lacrimal gland with increasing age was the progressive accumulation of lipofuscin-like inclusions in the cytoplasm of acinar cells. Lipofuscin is an accepted biomarker of aging and is composed of a heterogeneous group of complex autofluorescent aggregates derived from oxidative products of lipids, proteins and metal ions ${ }^{(36-38)}$. It accumulates progressively in lysosomes of postmitotic tissue because it is not totally eliminated either by degradation or exocytosis ${ }^{(39-41)}$. It has been demonstrated that lipofuscin accumulation in cells is accelerated under conditions of increased free radicals and oxidative stress.

It has become increasingly accepted that damage resulting from ROS, or oxidative stress, plays a role in the aging process. The level to which oxidative stress contributes to aging may vary between organisms, tissues and distinct cell types. The oxidative stress theory of aging proposes that ROS, which primarily result from normal mitochondrial metabolism, cause progressive damage resulting in the functional decline that defines aging.

For many years, evidence for the oxidative stress theory of aging was limited to correlative studies demonstrating that oxidative damage accumulates with age, or that the rate of accumulation of oxidative damage scales lifespan. Damage to DNA, protein and lipids has been shown to increase with age in humans. Reducing antioxidant defenses or increasing oxida- 


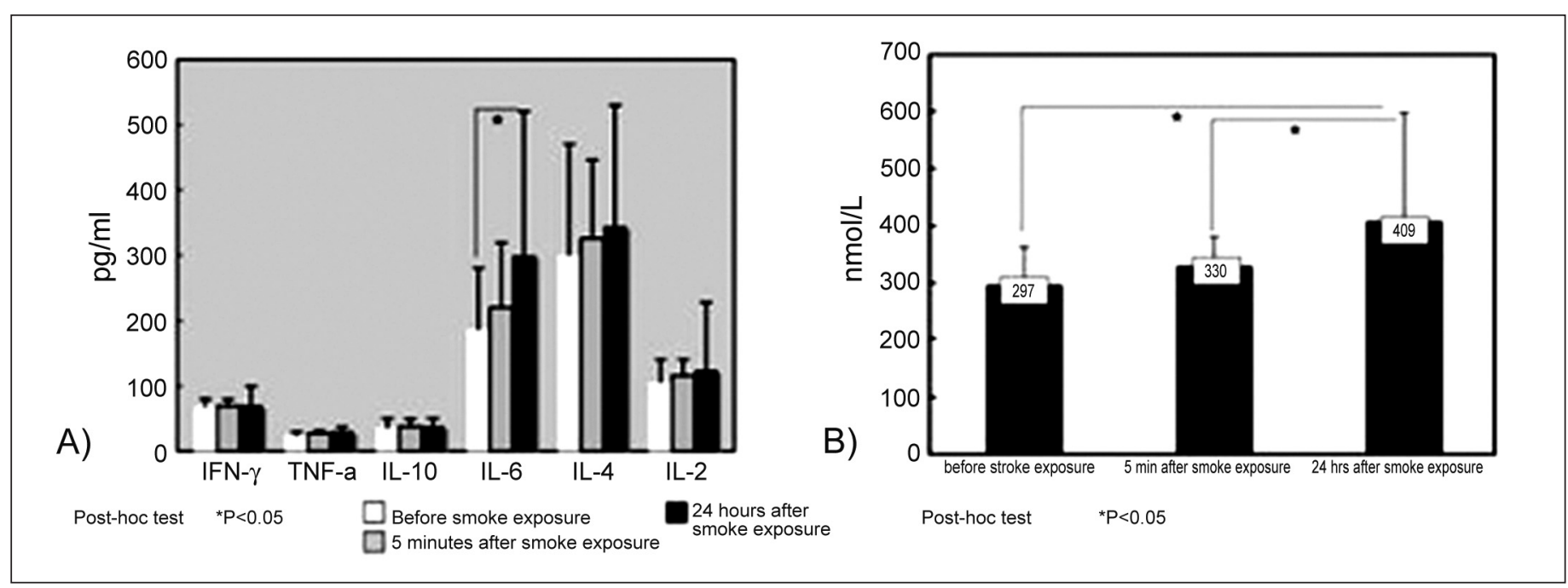

Figure 4 - A) The change in concentrations of tear cytokines with cigarette smoke exposure. Note that all the investigated tear cytokines were elevated $24 \mathrm{~h}$ after exposure to cigarette smoke exposure with a significant elevation in the mean IL-6 concentration. B) The change in the mean tear HEL concentration with passive cigarette smoke exposure. Note the signficant increase in the lipid peroxidation product, hexanoyl-lysine concentration $24 \mathrm{~h}$ after exposure to smoke. (Reprinted with permission from Elsevier. Cytokine, 2008 Aug; 43(2); in: Tear cytokine and ocular surface alterations following brief passive cigarette smoke exposure. Pages 203 and 204. Figures 4 and 5)

tive stress has resulted in a shortening of lifespan. Taken together, these correlative studies present a strong circumstantial case for universal involvement of oxidative stress in the aging process. Recently, the oxidative stress theory of aging has been tested in different sectors of Medicine.

In Ophthalmology, the relation between oxidative stress and aging has been given attention for some diseases to aging like age-related macular degeneration, cataract and dystrophy. Recently, Imamura et al. ${ }^{(1)}$ reported on the Sodl knockout(KO) mouse as a model mouse of age-related changes. Because the amount and activity of SOD1 are the highest among the three isoenzymes in the human retina, it seemed reasonable to hypothesize that the lack of SOD1 would accelerate age-related pathological changes in the human retina. Imamura et al. investigated the age-related changes of the retinas of Sodl KO mice and found that these mice have many of the key elements of human age-related macular degeneration including drusen, thickened Bruch's membrane, and retina neovascularization. Moreover, the retinal pigment epithelium (RPE) cells of these mice showed signs of oxidative stress damage, and their junctional integrities were damaged. Thus, their results suggest a causative role of oxidative stress in the pathogenesis of retinal degeneration and demonstrated a critical role of SOD1 in protecting the RPE from age-related degeneration.

Using the same mouse model, we reported that tear quantity and stability in the Sod1 KO mouse model were lower from 20 weeks to 50 weeks compared with the wild-type mice. The lacrimal gland of the Sod1 KO mouse showed significant inflammatory infiltrates and evidence of oxidative stress damage compared with wild-type mice. Although the Sod1 knockout mouse is known as a model mouse of aging, abnormal quantitative and qualitative findings observed in relation to the tear functions, ocular surface and lacri- mal gland histopathology suggest that it can also serve as a mouse model of dry eyes ${ }^{(42)}$ (Figure 5).

It is still unclear whether oxidative stress is the primary initiating event that is associated with some eye diseases. However, a growing body of evidence implicates it as being involved in at least the propagation of cellular injury that leads to eye pathology in these various conditions. It is biologically relevant in vivo and is intimately linked with an integrated series of cellular events. Interaction between these various components is not necessarily a cascade but might be a cycle of events, of which oxidative stress is a major component. Inhibition of oxidative stress therapeutically might act to "break the cycle" of cell death. The creation of numerous cell and animal models, which selectively target the effects of oxidative stress to the specifically affected eye region in each of the diseases, greatly advanced our understanding of involvement of oxidative stress in eye disease events.

\section{RESUMO}

Estresse oxidativo é causado por um desequilíbrio entre a produção de espécies reativas do oxigênio e a habilidade dos mecanismos de defesa do sistema biológico necessários para eliminar este estresse. $\mathrm{O}$ estresse oxidativo tem sido aceito como um fator envolvido em várias doenças agudas, crônicas e até mesmo no envelhecimento fisiológico. Recentemente, o crescente conhecimento dos danos causados pelo estresse oxidativo e a sua relação com doenças da superfície ocular estimulou pesquisadores a descobrir possíveis mecanismos no desenvolvimento da doença do olho seco. Esta revisão tem como foco a avaliação da influência do estresse oxidativo nas doenças do olho e enfatiza a sua relação com a patogênese da doença do olho seco. 


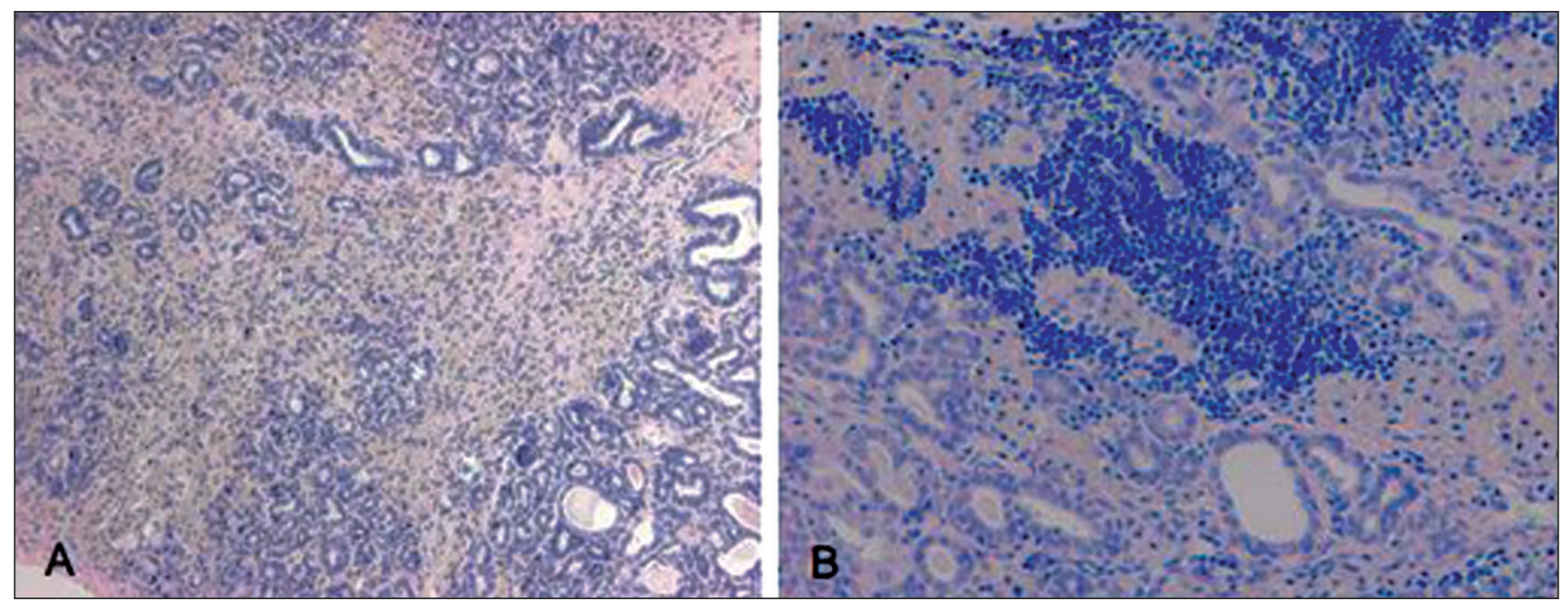

Figure 5 - Note the extensive perilobular fibrosis (A), infiltration around the acinar cells (B) and atrophy of the acinar units (A and B) in the Sod1 KO mouse lacrimal gland (H\&E, original magnification $\mathbf{x 2 0 0 )}$

Descritores: Estresse oxidativo; Lágrimas/enzimologia; Oftalmopatias; Síndromes do olho seco

\section{REFERENCES}

1. Imamura Y, Noda S, Hashizume K, Shinoda K, Yamaguchi M, Uchiyama S, et al. Drusen, choroidal neovascularization, and retinal pigment epithelium dysfunction in SOD1-deficient mice: a model of age-related macular degeneration. Proc Natl Acad Sci U S A. 2006;103(30):11282-7.

2. Spector A. Oxidative stress-induced cataract: mechanism of action. Faseb J. 1995;9(12):1173-82.

3. Gritz DC, Montes C, Atalla LR, Wu GS, Sevanian A, Rao NA. Histochemical localization of superoxide production in experimental autoimmune uveitis. Curr Eye Res. 1991;10(10):927-31.

4. Niesman MR, Johnson KA, Penn JS. Therapeutic effect of liposomal superoxide dismutase in an animal model of retinopathy of prematurity. Neurochem Res. 1997;22(5):597-605.

5. Alio JL, Ayala MJ, Mulet ME, Artola A, Ruiz JM, Bellot J. Antioxidant therapy in the treatment of experimental acute corneal inflammation. Ophthalmic Res. 1995;27(3):136-43

6. Alio JL, Artola A, Serra A, Ayala MJ, Mulet ME. Effect of topical antioxidant therapy on experimental infectious keratitis. Cornea. 1995;14(2):175-9.

7. Valentine JS, Doucette PA, Zittin Potter S. Copper-zinc superoxide dismutase and amyotrophic lateral sclerosis. Annu Rev Biochem. 2005;74:563-93.

8. Valko M, Morris H, Cronin MT. Metals, toxicity and oxidative stress. Curr Med Chem. 2005;12(10):1161-208

9. Drechsel DA, Patel M. Role of reactive oxygen species in the neurotoxicity of environmental agents implicated in Parkinson's disease. Free Radic Biol Med. 2008;44(11):1873-86.

10. Behndig A, Svensson B, Marklund SL, Karlsson K. Superoxide dismutase isoenzymes in the human eye. Invest Ophthalmol Vis Sci. 1998;39(3):471-5.

11. Halliwell B, Gutteridge JM. Oxygen toxicity, oxygen radicals, transition metals and disease. Biochem J. 1984;219(1):1-14

12. Kontos HA. George E. Brown memorial lecture. Oxygen radicals in cerebral vascular injury. Circ Res. 1985;57(4):508-16.

13. Tsubota K, Fukagawa K, Fujihara T, Shimmura S, Saito I, Saito K, et al. Regulation of human leukocyte antigen expression in human conjunctival epithelium. Invest Ophthalmol Vis Sci. 1999;40(1):28-34.

14. Iwata M, Kiritoshi A, Roat MI, Yagihashi A, Thoft RA. Regulation of HLA class II antigen expression on cultured corneal epithelium by interferon-gamma. Invest Ophthalmol Vis Sci. 1992;33(9):2714-21.

15. Mircheff AK, Gierow JP, Wood RL. Traffic of major histocompatibility complex class II molecules in rabbit lacrimal gland acinar cells. Invest Ophthalmol Vis Sci. 1994;35(11):3943-51.
16. Zoukhri D. Effect of inflammation on lacrimal gland function. Exp Eye Res 2006;82(5):885-98.

17. Baudouin C, Haouat N, Brignole F, Bayle J, Gastaud P. Immunopathological findings in conjunctival cells using immunofluorescence staining of impression cytology specimens. Br J Ophthalmol. 1992;76(9):545-9.

18. Baudouin C, Brignole F, Becquet F, Bayle J, Gastaud P. Immunopathological findings in conjunctival cells using immunofluorescence staining of impression cytology specimens Invest Ophthalmol Vis Sci. 1997;38(7):1458-64.

19. Nakamura S, Shibuya M, Nakashima H, Hisamura R, Masuda N, Imagawa T, et al. Involvement of oxidative stress on corneal epithelial alterations in a blinksuppressed dry eye. Invest Ophthalmol Vis Sci. 2007;48(4):1552-8.

20. Augustin AJ, Spitznas M, Kaviani N, Meller D, Koch FH, Grus F, et al Oxidative reactions in the tear fluid of patients suffering from dry eyes. Graefes Arch Clin Exp Ophthalmol. 1995;233(11):694-8.

21. Finkel T. Oxygen radicals and signaling. Curr Opin Cell Biol. 1998;10(2): 248-53.

22. Dalle-Donne I, Rossi R, Colombo R, Giustarini D, Milzani A. Biomarkers of oxidative damage in human disease. Clin Chem. 2006;52(4):601-23.

23. Rosette C, Karin M. Ultraviolet light and osmotic stress: activation of the JNK cascade through multiple growth factor and cytokine receptors. Science. 1996;274(5290):1194-7.

24. Kleiman NJ, Wang RR, Spector A. Ultraviolet light induced DNA damage and repair in bovine lens epithelial cells. Curr Eye Res. 1990;9(12):1185-93.

25. Shimmura S, Suematsu M, Shimoyama M, Tsubota K, Oguchi Y, Ishimura Y Subthreshold UV radiation-induced peroxide formation in cultured corneal epithelial cells: the protective effects of lactoferrin. Exp Eye Res. 1996;63 (5):519-26.

26. Forteza R. Casalino-Matsuda SM, Monzon ME, Fries E, Rugg MS, Milner CM, et al. TSG-6 potentiates the antitissue kallikrein activity of inter-inhibitor through bikunin release. Am J Respir Cell Mol Biol. 2007;36(1): 20-31.

27. Lima MF, Kierszenbaum F. Lactoferrin effects of phagocytic cell function. II. The presence of iron is required for the lactoferrin molecule to stimulate intracellular killing by macrophages but not to enhance the uptake of particles and microorganisms. J Immunol. 1987;139(5):1647-51.

28. Dogru M, Matsumoto Y, Yamamoto Y, Goto E, Saiki M, Shimazaki J, et al. Lactoferrin in Sjogren's syndrome. Ophthalmology. 2007;114(12):2366-7.

29. Satici A, Bitiren M, Ozardali I, Vural H, Kilic A, Guzey M. The effects of chronic smoking on the ocular surface and tear characteristics: a clinical, histological and biochemical study. Acta Ophthalmol Scand. 2003;81(6):583-7.

30. Altinors DD, Akca S, Akova YA, Bilezikçi B, Goto E, Dogru M, et al. Smoking associated with damage to the lipid layer of the ocular surface. Am J Ophthalmol 2006;141(6):1016-21

31. Pryor WA. Cigarette smoke and the involvement of free radical reactions in chemical carcinogenesis. Br J Cancer Suppl. 1987;8:19-23.

32. Matsumoto Y, Dogru M, Goto E, Sasaki Y, Inoue H, Saito I, et al. Alterations of the tear film and ocular surface health in chronic smokers. Eye. 2008; 22(7):961-8. 
33. Rummenie VT, Matsumoto Y, Dogru M, Wang Y, Hu Y, Ward SK, et al. Alterations of the tear film and ocular surface health in chronic smokers. Cytokine. 2008;43(2):200-8.

34. Schaumberg DA, Sullivan DA, Dana MR. Epidemiology of dry eye syndrome. Adv Exp Med Biol. 2002;506(Pt B):989-98.

35. Damato BE, Allan D, Murray SB, Lee WR. Senile atrophy of the human lacrimal gland: the contribution of chronic inflammatory disease. $\mathrm{Br} \mathrm{J}$ Ophthalmol. 1984;68(9):674-80.

36. Obata H, Yamamoto S, Horiuchi H, Machinami R. Histopathologic study of human lacrimal gland. Statistical analysis with special reference to aging. Ophthalmology. 1995;102(4):678-86.

37. Donato H, Jr., Hoselton MA, Sohal RS. Lipofuscin accumulation: effects of individual variation and selective mortality on population averages. Exp Gerontol. 1979;14(3):141-7.
38. Terman A, Brunk UT. Ceroid/lipofuscin formation in cultured human fibroblasts: the role of oxidative stress and lysosomal proteolysis. Mech Ageing Dev. 1998;104(3):277-91.

39. Sitte N, Huber M, Grune T, Ladhoff A, Doecke WD, Von Zglinicki T, et al. Proteasome inhibition by lipofuscin/ceroid during postmitotic aging of fibroblasts. Faseb J. 2000;14(11):1490-8.

40. Spiteller G. Lipid peroxidation in aging and age-dependent diseases. Exp Geronto.1 2001;36(9):1425-57.

41. Brunk UT, Terman A. Lipofuscin: mechanisms of age-related accumulation and influence on cell function. Free Radic Biol Med. 2002;33(5):611-9.

42. Wakamatsu T, Dogru M, Sasaki Y, Ward S, Imamura Y. Histopathological alterations in senescent $\mathrm{Cu}, \mathrm{Zn}$-superoxide dismutase-1 (Sod-1)-knock-out mice: a new model for dry eye. In: $5^{\text {th }}$ International Conference on the Tear Film and Ocular Surface. Taormina. Italy, September 4-9, 2007. 